Nanomaterials, Nanotechnologies, 11 (3), 519-549. Erratum: ibid, (2014)., 12 (2), 415.

2. Kruglyak, Yu. A. (2013). From Ballistic Conductivity to Diffusional in the Landauer-Datta-Lunstrom. Transport Model, Nanosystems, Nanomaterials, Nanotechnologies, 11 (4), 655-677.

3. Kruglyak, Yu. A. (2014). Thermoelectric phenomena and devices in the Landauer-Datta-Lunstrom approach. ScienceRise, 3/2(5), 73-88. doi: 10.15587/23138416.2014.27967

4. Lundstom, M., Guo, J. (2006). Nanoscale Transistors: Physics, Modeling, and Simulation. Berlin: Springer, 218.

5. Kim, R., Lundstrom, M. S. Notes on Fermi - Dirac Integrals. Purdue University. Available at: www.nanohub.org/resources/5475

6. Lundstrom, M., Jeong, C. (2013). Near-Equilibrium Transport: Fundamentals and Applications. Hackensack, New Jersey: World Scientific Publishing Company. Available at: www.nanohub.org/resources/11763

7. Sommerfeld, A. (1928). An electronic theory of the metals based on Fermi's statistics. Journal of Physics, 47 (1), 1.
8. Ashcroft, N. W., Mermin, N. D. (1979). Solid State Physics (Philadelphia: Suanders College, 486.

9. Geballe, T. N., Hull, G. W. (1954). Seebeck Effect in Germanium, Physical Review, 94 (5), 1134-1140. doi: 10.1103/physrev.94.1134

10. Pierret, R. F. (1996). Semiconductor Device Fundamentals. Reading, MA: Addison-Wesley, 792.

11. Kim, R. S. (2011). Physics and Simulation of Nanoscale Electronic and Thermoelectric Devices. West Lafayette: Purdue University, 218.

12. Supriyo, D. (2012). Lessons from Nanoelectronics: A New Perspective on Transport. Hackensack, New Jersey: World Scientific Publishing Company, 473. Available at: www.nanohub.org/courses/FoN1

13. Kruglyak, Yu. A., Kruglyak, N. Yu., Strikha, M. V. (2013). Lessons of nanoelectronics. Thermoelectric phenomena in «bottom - up» approach, Sensor Electronics Microsys. Tech., 13 (1), 6-21.

14. Kruglyak, Yu. A. (2013). Lessons of nanoelectronics. 4. Thermoelectric phenomena in «bottom - up» approach. Physics in Higher Education, 19 (4), 70-85.

Рекомендовано до публікації д-р фіз.-мат. наук Глуиков О. В. Дата надходження рукопису 15.12.2014

Кругляк Юрій Олексійович, доктор хімічних наук, профессор, кафедра інформаційних технологій, Одеський державний екологічний університет, вул. Львівська, 15, м. Одеса, Україна, 65016

E-mail: quantumnet@yandex.ua

УДК 537.622: 544.227: 621.318.1

DOI: 10.15587/2313-8416.2015.36410

\title{
МАГНИТНАЯ И ЭЛЕКТРОННО-ИОННАЯ СТРУКТУРА MnZn-ФЕРРИТОВ В ПРИПОВЕРХНОСТНЫХ СЛОЯХ, ОБЕДНЕННЫХ И ОБОГАЩЕННЫХ ЦИНКОМ
}

\section{(C) А. В. Копаев, В. В. Мокляк, В. С. Бушкова}

Исследованы процессы, происходящчие на атомном уровне вблизи поверхности феррита $\mathrm{Mn}_{0.6} \mathrm{Zn}_{0.3} \mathrm{Co}_{0.05} \mathrm{Fe}_{2.05} \mathrm{O}_{4}$, полученных в различных условиях - стандартной и специиальной атмосфере. Предлагаемый способ насыщения циинком поверхностных слоев феррита частично восстанавливает не только химический состав, но и магнитную структуру вблизи поверхности ферритовых изделий

Ключевые слова: марганеи-иинковый феррит, насыщение ичинко, рентгеновская спектроскопия поглощения, мессбауэровская спектроскопия

It is investigated the processes occurring at the atomic level near the surface of the ferrite $\mathrm{Mn}_{0.6} \mathrm{Zn}_{0.3} \mathrm{Co}_{0.05} \mathrm{Fe}_{2.05} \mathrm{O}_{4}$, obtained in different conditions - standard and special atmospheres. The proposed method of Zn-saturation of the surface layers of ferrite partially recovers not only the chemical composition but also the magnetic structure near the surface of the ferrite products

Keywords: manganese-zinc ferrite, saturation with zinc, X-ray absorption spectroscopy, Mössbauer spectroscopy

\section{1. Введение}

Среди материалов с высокой магнитной проницаемостью марганец-цинковые ферриты со структурой шпинели занимают важное место. Они имеют высокое электрическое сопротивление и низкие потери энергии в переменных магнитных полях. Их технология сравнительно проста и хорошо освоена, однако пока еще не оптимальна. \section{публикаций \\ 2. Постановка проблемы и анализ \\ Одна из проблем $[1,2]$, которая пока еще не} полностью решена, состоит в следующем. Известно, что цинк, входящий в состав феррита, при температурах синтеза выше $1000{ }^{\circ} \mathrm{C}$ обладает высокой упруго- стью паров над поверхностью твердой фазы $[3,4]$. При этом вблизи поверхности образцов материал обедняется цинком. Отклонения элементного состава в приповерхностном слое ферритов приводит к неконтролируемым изменениям и к ухудшению электромагнитных параметров изделий.

Мы сопоставили табличные данные из $[3,4]$ и представили их в виде графиков зависимости логарифма скорости испарения цинка от обратной температуры синтеза при данном давлении кислорода (рис. 1). Как видно из рисунка, эта зависимость практически линейная для данного химического состава феррита. Анализ показывает, что скорость испарения цинка тем выше, чем больше температура и концентрация цинка в твердофазной матрице, а также чем меньше парциальное 
давление кислорода в среде. Однако повышение давления кислорода при синтезе феррита, хотя и приводит к снижению летучести цинка, повышает вероятность окисления марганца до состояния +3 и ведет к ухудшению электромагнитных параметров марганеццинковых ферритов [5].

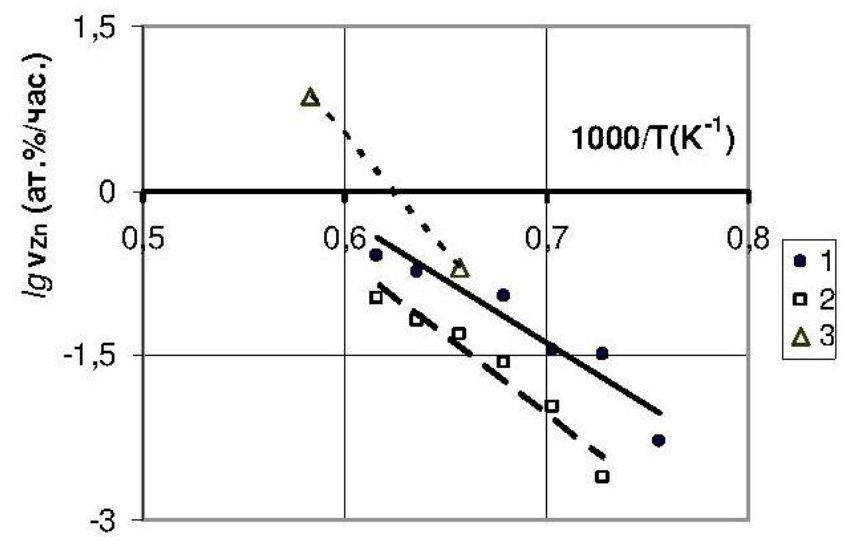

Рис. 1. Зависимость скорости испарения цинка от температуры обжига MnZn-ферритов разного состава при различных давлениях кислорода: $1-\mathrm{p}_{\mathrm{O} 2}=0.27 \cdot 10^{-3}$ aтм; $2-\mathrm{p}_{\mathrm{O} 2}=0.27 \cdot 10^{-2} \mathrm{aTM}$ $3-\mathrm{p}_{\mathrm{O} 2}=0.27$ атм; $1,2-$ феррит состава $\mathrm{Mn}_{0.60} \mathrm{Zn}_{0.28} \mathrm{Fe}_{2.12} \mathrm{O}_{4}[2] ; 3$ - феррит $\mathrm{ZnFe}_{2} \mathrm{O}_{4}$ [3]

Нами было предложено проводить синтез ферритов данного состава в прежнем кислородном режиме, но в присутствии образцов с повышенным содержанием цинка (например, цинкового феррита). Последние, их можно назвать «эмиттерами», насыщали атмосферу парами цинка вблизи серийных изделий и вследствие соблюдения термодинамического равновесия атомы цинка обогащали их приповерхностный слой, переходя из газовой среды в твердую матрицу.

Представляет интерес, как такой метод повлияет на электронно-ионную и магнитную структуру приповерхностных слоев марганец-цинковых ферритов. Согласно [6], электронная структура катионов переходных 3d-металлов в соединениях с кислородом успешно исследуется с помощью рентгеновских спектров поглощения. К-края поглощения марганца и железа несут информацию также о характере химической связи в соединении. При этом принимается во внимание как тонкая структура краев поглощения (XANES, EXAFS), так и энергия положения самого К-края. Согласно опубликованным экспериментальным данным, смещение К-края поглощения элемента в составе феррита относительно металла соответствует средней степени окисленности ионов марганца в MnZn-ферритах близко двум, а железа - трем $[7,8]$. Однако изменение режима синтеза и спекания ферритов приводит к корректировке зарядов ионов, что может быть с высокой точностью обнаружено по смещению К-края поглощения катиона [9].

Анализ мессбауэровских спектров поглощения $\mathrm{MnZn-ферритов} \mathrm{на} \mathrm{ядрах}{ }^{57} \mathrm{Fe}$ показывет, что квадрупольное расщепление в них близко к нулю, а химический сдвиг соответствует степени окисленности ионов железа +3 . Однако на величину сдвига влияют также другие характеристики химической связи и кристалли- ческой структуры. В связи с этим наиболее информативным является катионное распределение по неэквивалентным позициям в кристалле шпинели - тетраэдрическим и октаэдрическим (А и $\left.\mathrm{B}_{1}, \mathrm{~B}_{2}, \ldots\right)$ и соответствующие им эффективные магнитные поля на ядрах ${ }^{57} \mathrm{Fe}$. При достаточно высоких температурах (для указанных ферритов это комнатная температура) замещение магнитного иона $(\mathrm{Fe}, \mathrm{Mn})$ на немагнитный $(\mathrm{Zn})$ снижает эффективные поля для каждого неэквивалентного окружения мессбауэровского ядра $[10,11]$.

Как следует из изложенного, рентгеноспектральный и мессбауэровский методы исследований позволяют получить информацию о процессах, протекающих на атомном уровне при изменении состава феррита во время температурной обработки.

\section{3. Экспериментальная часть}

В настоящей работе исследованы процессы, протекающие на атомном уровне вблизи поверхности изделий из ферритов. Образцы $\mathrm{MnZn-феррита} \mathrm{про-}$ мышленной марки исходного состава $\mathrm{Mn}_{0.6} \mathrm{Zn}_{0.3} \mathrm{Co}_{0.05} \mathrm{Fe}_{2.05} \mathrm{O}_{4}$ в виде массивных изделий получены по керамической технологии в различных условиях - в типовой и специальной газовых средах. Типовая атмосфера (разреженный воздух) обеспечивала необходимое валентное состояние катионов металлов в феррите данного химического состава. В другой (специальной) газовой среде при неизменных регулировках давления воздуха содержание паров цинка определялось наличием «эмиттеров». После высокотемпературной обработки при $1270{ }^{\circ} \mathrm{C}$ с поверхности $\mathrm{MnZn}$ ферритов снимались алмазным инструментом слои материала толщиной 50 мкм. Полученные пробы исследовались методами мессбауэровской и рентгеновской спектроскопии на просвет. Исследования магнитной структуры мессбауэровским методом проводилось на установке MS1104EM, где источником гаммаквантов служил ${ }^{57}$ Со в хромовой матрице. Компьютерная обработка спектров проводилась по программе UNIVEM 7.02. Распределение электронной плотности на ионах железа и марганца исследовалось методом рентгеновских К-краев поглощения. Спектры поглощения снимались на длинноволновом спектрометре ДРС на фотопленку и затем обрабатывались на микрофотометре с применением компьютера. Кроме того рентгенофлуоресцентным методом в данных (тонких) пробах определялся химический состав по специальной методике [12].

\section{4. Обсуждение результатов исследований}

Рентгеноструктурные исследования показали присутствие во всех пробах только одной кристаллической фазы шпинели типа $\mathrm{A}\left[\mathrm{B}_{2}\right] \mathrm{O}_{4+\delta}$, где $\mathrm{A}-$ катионы в тетраэдрических позициях, образованных анионами кислорода; В - катионы в октаэдрических позициях.

На рис. 2 показано, что К-край поглощения рентгеновских лучей в ферритах смещен относительно металлического состояния (отсчет ведется по положению середины главного склона края) в сторону высоких энергий. В основе интерпретации смещения края рентгеновского поглощения лежит правило Кунцля, многократно подтвержденное экспериментально и обоснованное теоретически [7]. 


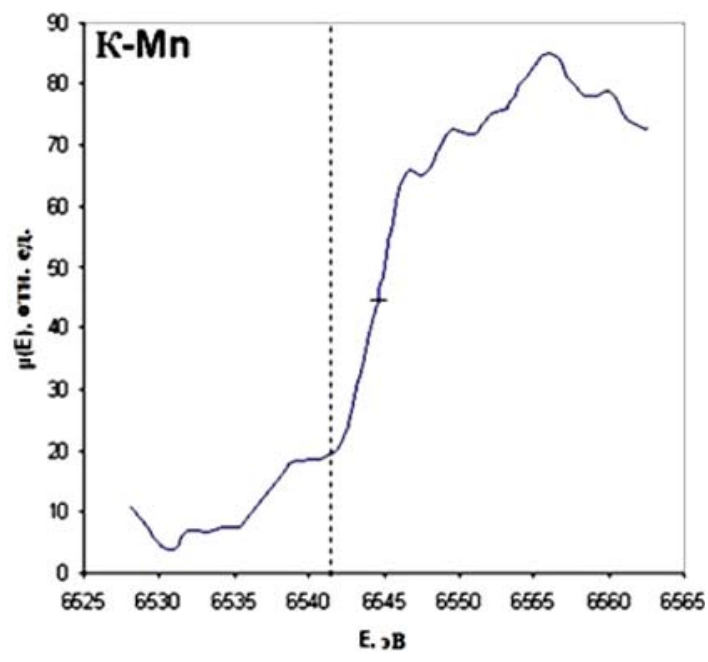

a

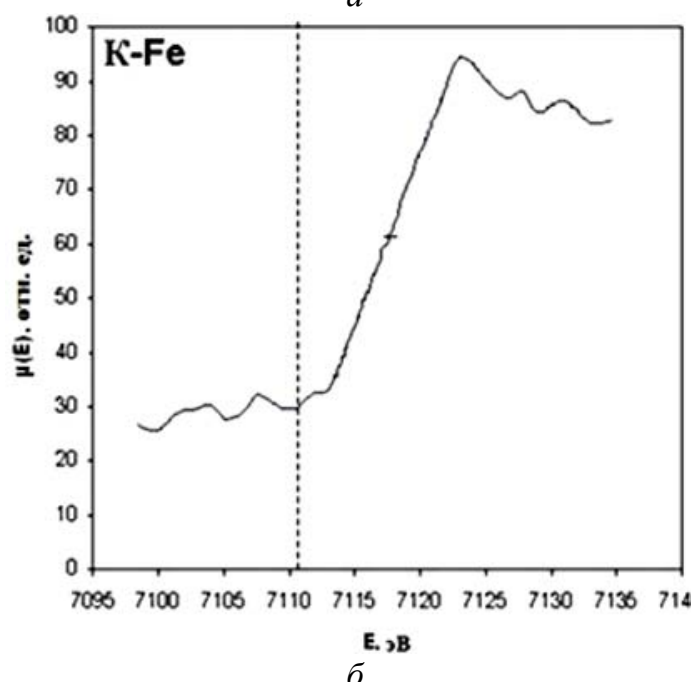

Рис. 2. К-края рентгеновского поглощения атомов металлов в соединении $\mathrm{MnZn-феррита} \mathrm{(объем} \mathrm{образца,}$ типовая технология). Показана метка - середина склона, по которой определялось положение края, штриховая линия указывает положение края у свободного металла: $a$ - марганец; $\sigma$ - железо

При увеличении положительного заряда 3dатома металла при образовании соединения с кислородом снижается экранирование электронов внутренних оболочек атомов валентными электронами, а ряд незанятых уровней смещается от уровня Ферми в сторону запрещенной зоны. В результате при повышении степени окисленности К-край смещается в сторону высоких энергий. Наши исследования показали (рис. 3), что использование специальной среды обжига приводит к значительному окислению ионов железа (ошибка измерения \pm 0.2 эВ) непосредственно у поверхности феррита и незначительному - ионов марганца.

Для К-края соединений переходных металлов, чья локальная симметрия вокруг поглощающего атома тетраэдрическая, наблюдается предкраевая тонкая структура - наплыв (рис. 2). Он не может быть отнесен к квадрупольному переходу $1 \mathrm{~s}->3 \mathrm{~d}$, так как, согласно расчетам [13], вероятность такого перехода очень мала. Поэтому достаточно сильная абсорбция в районе энергии 6540 эВ в спектре марганца обязана все же дипольному переходу. Незанятые р-орбитали сильно гибридизуются с d-зоной в соединениях с тетраэдрической симметрией, где как р- так и d-орбитали принадлежат молекулярной орбитали $\mathrm{t}_{2}$, что можно показать, используя теорию групп. Поэтому интенсивный электрический дипольный переход наблюдается в диапазоне энергий незаполненной d-зоны. C другой стороны p- и d- орбитали никогда не смешиваются между собой при наличии октаэдрической симметрии. На спектре К-края железа, ионы которого размещаются в основном в октаэдрах, интенсивность наплыва в области низких энергий значительно слабее, чем на спектре марганца.

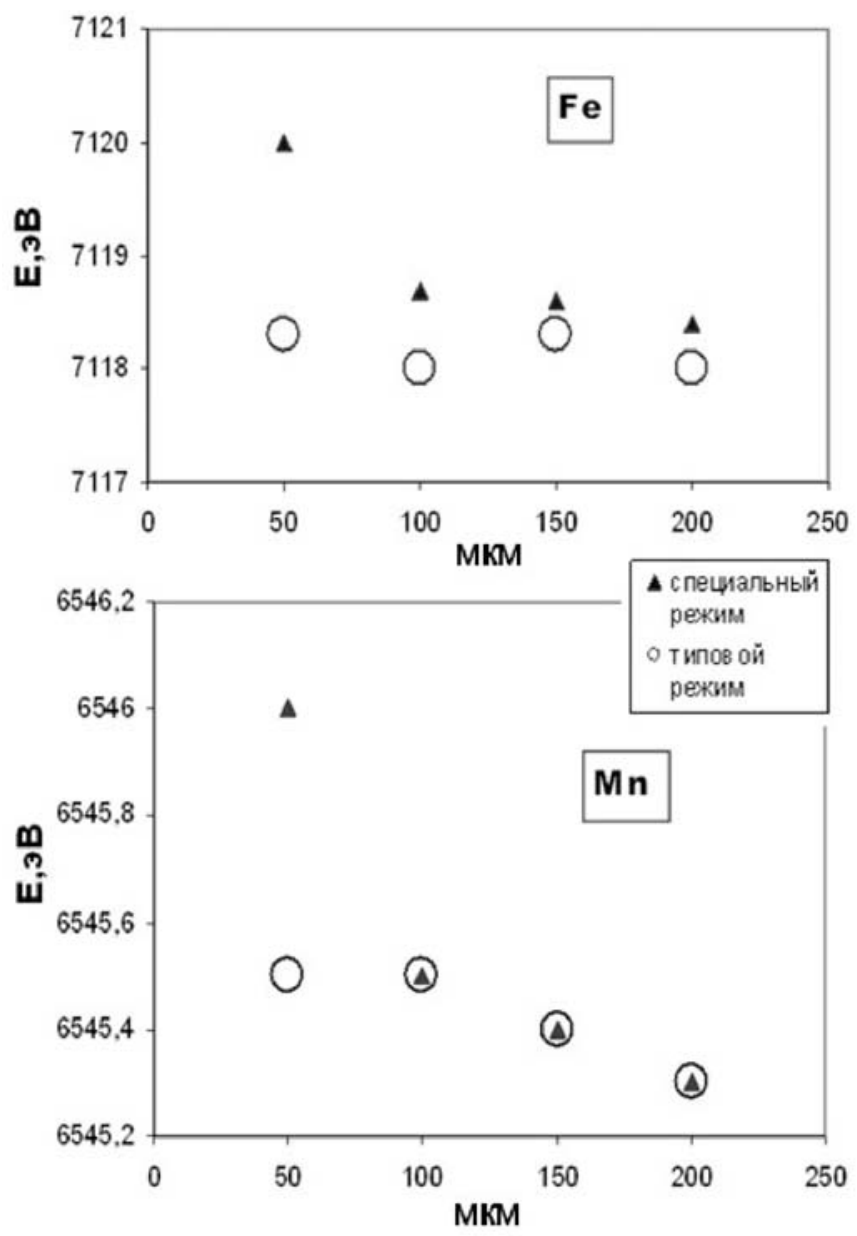

Рис. 3. Зависимость смещения К-края поглощения железа и марганца в пробах MnZn- ферритов от положения проб относительно поверхности изделия

Как показали мессбауэровские исследования, в гамма-резонансных спектрах преобладает В-компонента с большим количеством составляющих секстетов от различных магнито-неэквивалентных положений ядер $\mathrm{Fe}^{57}$. Цинк размещается только в A-подрешетке, а оставшиеся тетраэдрические позиции, в основном, занимают ионы марганца, у которых реализуется сильное предпочтение к этим узлам. На рис. 4 представлен спектр от пробы, взятой с глубины 200 мкм образца, полученного по типовой технологии. Все остальные спектры внешне похожи друг на друга. Однако рассчеты показали существенную разницу между ними в значениях среднего эффективного поля на ядрах $\mathrm{Fe}$ в В-подрешетке ( $\left.{ }^{\mathrm{B} e}\right)$ (рис. 5). 


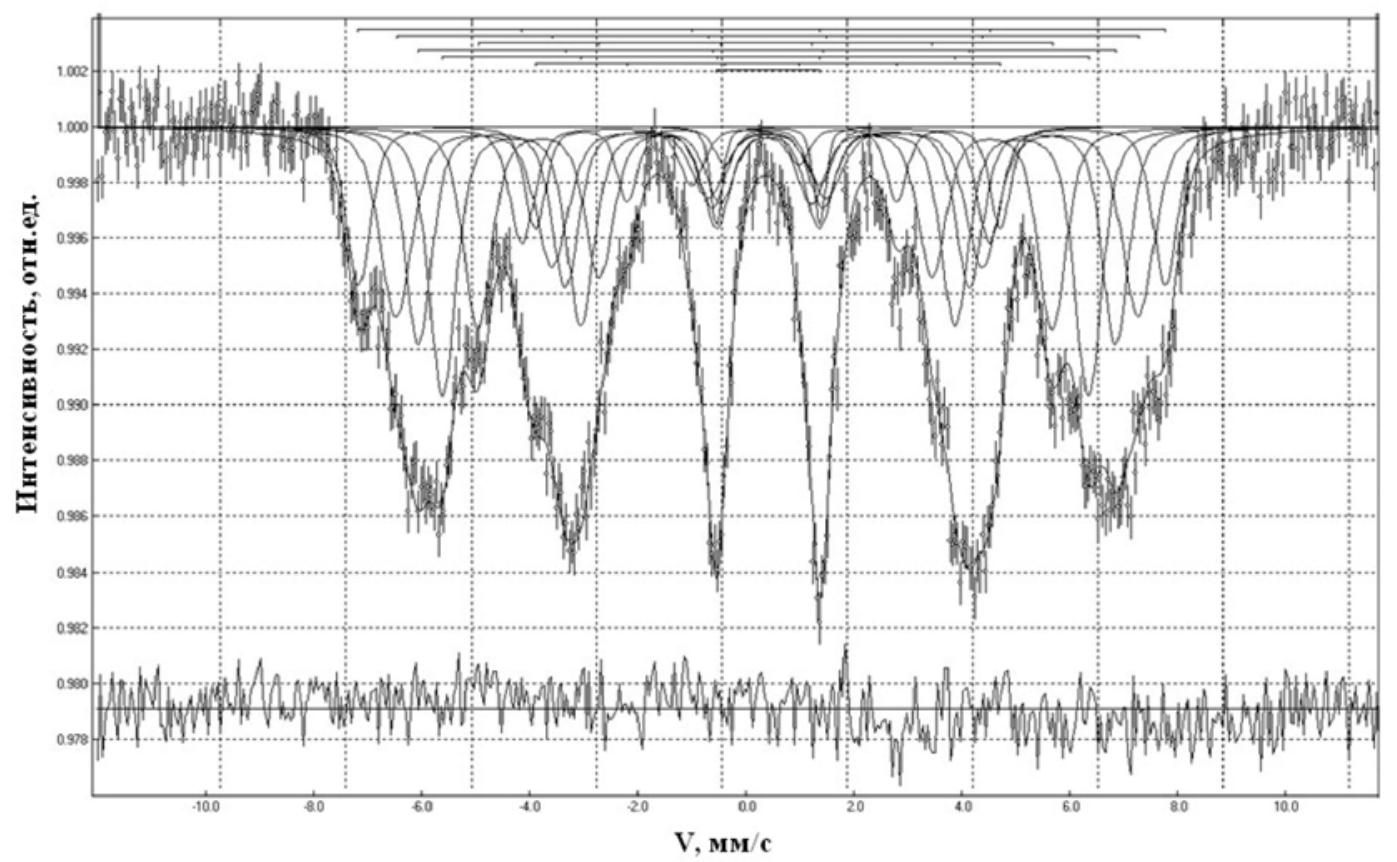

Рис. 4. Мессбауэровский спектр ${ }^{57} \mathrm{Fe}$ в пробе MnZn-феррита. Показано компьютерное представление спектра в виде шести секстетов и одного дублета

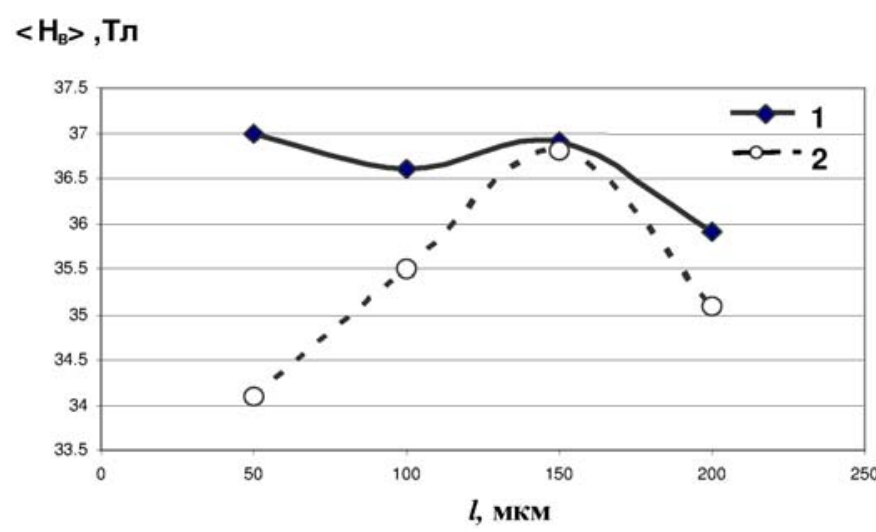

Рис. 5. Зависимость среднего эффективного поля на ядрах ${ }^{57} \mathrm{Fe}$ в В-подрешетке шпинели от положения пробы в образцах MnZn-феррита относительно поверхности: 1 - типовой режим; 2 - опытный режим

При этом учитывалось, что у тетраэдрических атомов в MnZn-феррите все ближайшие катионы магнитны [14]. Остальные поля суммировали с учетом парциального вклада каждого секстета. Как видно из рис. 5, в пробе, взятой с поверхности «типового» образца, эффективное поле выше, чем в глубине образца. Это связано с тем, что в ближайшем окружении ядер ${ }^{\mathrm{B}} \mathrm{Fe}$, число немагнитных катионов $\mathrm{Zn}^{2+}$ уменьшилось. Данный вывод следует из полученного нами выражения для среднего поля на ядре атома ${ }^{\mathrm{B}} \mathrm{Fe}$ в шпинели [15]:

$$
\left\langle{ }^{B} H\right\rangle=H_{0}\left[\sum_{n=0}^{3}(6-n) P(n, x)\right]^{k},
$$

где $x$ - атомные доли цинка в формуле феррита;

$P(n, x)$ - вероятность ближайшего окружения атома ${ }^{\mathrm{B}} \mathrm{Fe}$, когда из шести ближайших соседей $n$ атомов металлов немагнитны; $H_{0}$ - эффективное поле на ядре $\mathrm{Fe}$ в октаэдрической позиции при $n=0 ; k$-константа для данной структуры.

На снижение концентрации цинка в приповерхностном слое типового образца указывает и рентгенофлуоресцентный количественный анализ проб.

В специальной среде эффективное поле вблизи поверхности образца значительно меньше, чем в типовой. Причем, оно возрастает с глубиной взятия пробы и далее практически не отличается от поля в пробах типового образца. Такая зависимость обусловлена следующими процессами.

В процессе спекания в специальной среде цинк сначала испаряется из MnZn-феррита, как и при обычном спекании, а затем для соблюдения термодинамического равновесия атомы цинка из «эмиттеров» через газовую среду обжига насыщают обедненную поверхность образцов. Динамика эффективных полей показывает (рис. 5), что насыщение цинком происходит неравномерно: больше у поверхности и меньше в глубине образцов, согласно законам диффузии. Приблизительно на глубине 150 мкм и более магнитная структура и химические составы образцов, полученных по типовому и специальному режимам, уравниваются (ошибка в измерении полей составляет $\pm 0,3$ Тл).

При испарении цинка из матрицы феррита в ней могут протекать или преобладать по крайней мере два процесса:

1. Образование катионных вакансий в А-подрешетке в узлах, где размещались атомы цинка. В этом случае магнитные поля на ядрах железа не должны существенно измениться. Действительно, замена катионов $\mathrm{Zn}^{2+}$ с нулевым магнитным моментом немагнитными вакансиями не должно существенно повлиять на среднюю величину эффективного магнитного поля на ${ }^{\mathrm{B}} \mathrm{Fe}$.

2. Перестройка кристаллической и, следовательно, магнитной структуры шпинели. При растворе- 
нии восстановленных катионов $\mathrm{Fe}^{2+}$ в В-подрешетке может происходить вытеснение ионов $\mathrm{Fe}^{3+}$ и/или $\mathrm{Mn}^{2+}$ в вакантные места А-подрешетки. При этом эффективные поля на ядре ${ }^{\mathrm{B}} \mathrm{Fe}$ должны возрасти, поскольку указанные катионы обладают значительным магнитным моментом $\left(5 \mu_{\text {Б }}\right)$.

Как показали мессбауэровские исследования, в образце, полученном по типовой технологии, среднее эффективное поле возрастает с приближением к поверхности. Это, согласно изложенным

представлениям, указывает на перестройку кристаллической структуры при снижении концентрации цинка за счет его испарения.

В связи с большим количеством магнитонеэквивалентных позиций в структуре шпинели представляет

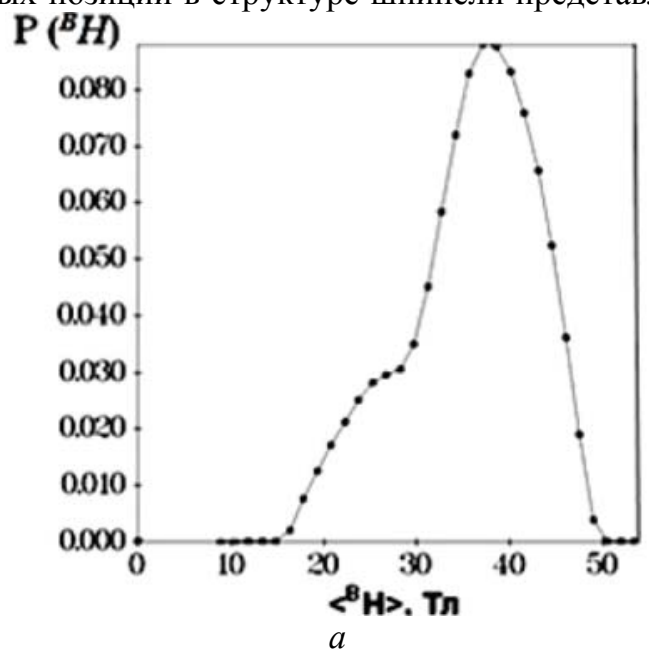

Рис. 6. Средние вероятности $\mathrm{P}\left({ }^{B} H\right)$ распределения сверхтонких магнитных полей на ядрах ${ }^{\mathrm{B}} \mathrm{Fe}$ в образце марганеццинкового феррита, полученного по типовой технологии: $a$ - объем образца; $\sigma$ - поверхность образца .

В заключение авторы благодарят В. Б. Медведникова за подготовку образцов и практические замечания, которые были учтены, и Ю. Н. Тафийчука за помощь, оказанную при обработке мессбауэровских спектров.

\section{5. Выводы}

1. Предложенный новый метод насыщения приповерхностных слоев марганец-цинковых ферритов цинком частично восстанавливает не только химический состав но и магнитную структуру вблизи поверхности ферритовых изделий.

2. Показано, что при этом возрастает степень окисленности железа, а валентное состояние марганца практически не изменяется, что важно особенно для обеспечения требуемых электромагнитных свойств низкоразмерных изделий из цинк-содержащих ферритов.

\section{Литература}

1. Летюк, Л. М. Технология ферритовых материалов магнитоэлектроники [Текст] / Л. М. Летюк , В. Г. Костишин , А. В. Гончар. - М.: МИСиС, 2005. - 352 с.

2. Kilbride, I. P. Effect of sintering enclosures and sintering parameters on the magnetic properties of a high permeability manganese-zinc ferrite [Text] / I. P. Kilbride, R. Freer // IEEE Transactions on Magnetics. - 2000. - Vol. 36, Issue 1. - P. 375380. doi: $10.1109 / 20.822550$

3. Стахиева, Т. В. Испарение цинка из MnZnферритов при их синтезе [Текст] / Т. В. Стахиева, К. А. Пис- интерес распределение полей на ядрах ${ }^{\mathrm{B}} \mathrm{Fe}$ в указанных пределение полей содержит слабо интенсивную полосу в диапазоне низких значений поля (рис. $6, a$ ). Согласно экспериментальным данным $[14,16]$, этот эффект можно интерпретировать, как плохо разрешенное дискретное распределение на ядрах ионов $\mathrm{Fe}^{2+}$ в матрице шпинели. Их пристутствие мы связываем с наличием мезоскопических образований - кластеров вюститного типа различных размеров в MnZn-феррите с анионными вакансими $[17,18]$. При испарении цинка из приповерхностных слоев образца концентрация анионных вакансий снижается и кластеры практически пропадают, на что указывает отсутствие слабых полей в спектре (рис. 6, б).

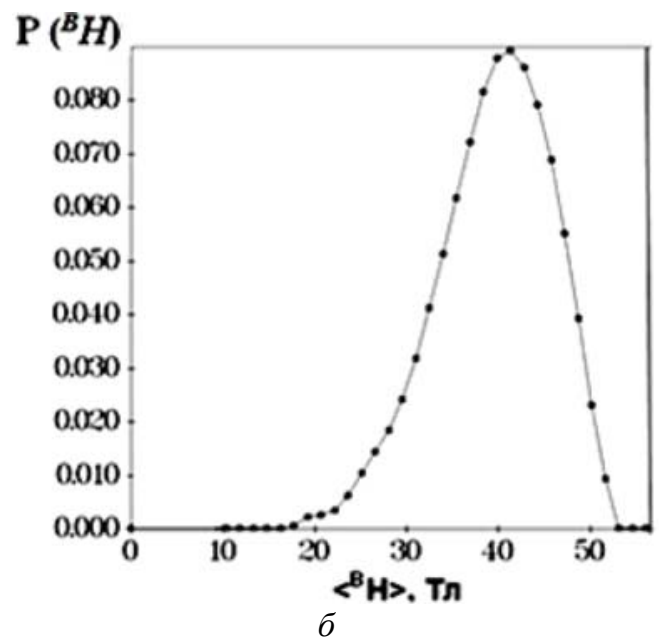
техника, 1974. - С. 97-102.

4. Brownlow, J. Preferential volatillization of cations from Ferrites During Sintering [Text] / J. Brownlow // Journal of Applied Physic. - 1958. - Vol. 29, Issue 3. - P. 373-375. doi: $10.1063 / 1.1723140$

5. Goldman, A. Modern ferrite technology. $2^{\text {nd }}$ Edition [Text] / A. Goldman. - Pittsburgh: Springer Science+Business Media. Inc, 2006. - 464 p.

6. Kawai, J. Absorption techniques in X-ray spectrometry [Text] / J. Kawai; R. A. Meyers (Ed.). - Enciclopedia of analytical chemistry. Vol. 15. - Chichester: John Wiley, 2000. P. $13288-13311$.

7. Lenglet, $M$. Contribution de la spectrometrie $\mathrm{X}$ d'oxides de per a valence mixte. Analise de la structure fine du seuil d'absorption K [Text] / M. Lenglet, D. Le Calonnec, J. Durr et. al // Materials Research Bulletin. - 1983. - Vol. 18, Issue 8. P. 935-944. doi: 10.1016/0025-5408(83)90004-1

8. Sacurai, S. Cation distribution and valence state in $\mathrm{Mn}$ Zn ferrite examined by synchrotron X-rays [Text] / S. Sacurai, S. Sasaki, M. Okube et al. // Physica B: Condensed Matter. 2008. - Vol. 403, Issue 19-20. - P. 3589-3595. doi: 10.1016/j.physb.2008.05.035

9. Fatemi, D. J. X-ray absorption, neutron diffraction, and Mössbauer effect studies of MnZn-ferrite processed through highenergy ball milling [Text] / D. J. Fatemi, V. G. Harris, M. X. Chen et al. // Journal of Applied Physics. - 1999. - Vol. 85, Issue 8. - P. 5172-5174 doi: 10.1063/1.369114

10. Gupta, R. G. Mössbauer stidies in $\mathrm{Zn}_{\mathrm{x}} \mathrm{Mn}_{1-\mathrm{x}} \mathrm{Fe}_{2} \mathrm{O}_{4}$ systems [Text] / R. G. Gupta, R. G. Mendiratta // Journal of Applied Physics. - 1977. - Vol. 48, Issue 2. - P. 845-848. doi: $10.1063 / 1.323642$ образцах. Так в глубоких слоях типового феррита, рас- 
11. Nasr Isfahani, M. J. A Mössbauer effect investigation of the formation of MnZn nanoferrite phase [Text] / M. J. Nasr Isfahani, M. Myndyk et al. // Journal of Alloys and Compounds. 2009. - Vol. 470, Issue 1-2. - P. 434-437. doi: $10.1016 /$ j.jallcom.2008.02.113

12. Копаєв, О. В. Особливості рентгенофлуорецентного аналізу феритів у тонких пробах [Текст] / О. В. Копаєв // Вісник Прикарпатського університету. Серія природничоматематичних наук. $-1995 .-$ Вип. 1. - С. 15-23.

13. Майзель, А. Рентгеновские спектры и химическая связь [Текст] / А. Майзель, Г. Леонхардт, Р. Сарган. - Киев: Наукова думка, 1980. - 420 с.

14. Vandenberghe, R. E. Mössbauer effect studies of oxidic spinels [Text] / R. E. Vandenberghe, E. De Grave; G. J. Long, F. Grandjean (Eds.). - Mössbauer spectroscopy applied to inorganic chemistry. Vol. 3. - New York: Plenum Press, 1989. P. 59-182. doi: 10.1007/978-1-4899-2289-2_3

15. Копаєв, О. В. Магнітне впорядкування в структурі нікелевих феритів / О. В. Копаєв // Фізика і хімія твердого тіла. - 2008. - Т. 9, № 1. - С. 58-63.

16. Campbell, S. J. Evaluation of distributed hyperfine parameters [Text] / S. J. Campbell, F. Aubertin; G. J. Long, F. Grandjean (Eds.). - Mössbauer spectroscopy applied to inorganic chemistry. Vol. 3. - New York: Plenum Press, 1989. P. 183-242. doi: 10.1007/978-1-4899-2289-2 4

17. Архаров, В. И. Проявление кластеризации структуры марганец-цинковых ферритов в рассеянии рентгеновских лучей [Текст] / В. И. Архаров, 3. А. Самойленко и др. // Изв. АН СССР. Неорган. Материалы. - 1991. - Т. 27, № 10. C. $2184-2189$.

18. Пащенко, В. П. Дефектность наноструктуры и магниторезистивные свойства марганец-цинковых ферритов [Текст] / В. П. Пащенко, А. А. Хорьяков и др. // Металлофиз. новейшие технолог. - 2009. - Т. 31, № 2. - С. 249-261.

\section{References}

1. Letyuk, L. M., Kostyshin, V. G., Gonchar, A. V. (2005). Technologija ferritovych materialov magnitoelektroniki. Moscow: Metallurgy, 352.

2. Kilbride, I. P., Freer, R. (2000). Effect of sintering enclosures and sintering parameters on the magnetic properties of a high permeability manganese-zinc ferrite. IEEE Transactions on Magnetics, 36 (1), 375-380. doi: 10.1109/20.822550

3. Stachijeva, T. V., Piskarjov, K. A. (1974). Isparenije zinka iz MnZn-ferritov pri ikh sintese. Struktura i svoystva ferritov, Minsk: Nauka i technika, 97-102.

4. Brownlow, J. (1958). Preferential volatillization of cations from Ferrites During Sintering. Journal of Applied Physic, 29 (3) 373-375. doi: 10.1063/1.1723140

5. Goldman, A. (2006). Modern ferrite technology. $2^{\text {nd }}$ Ed. Pittsburgh: Springer Science+Business Media. Inc, 464 .
6. Kawai, J.; Meyers, R. A. (Ed.) (2000). Absorption techniques in X-ray spectrometry. Enciclopedia of analytical chemistry. Vol. 15. Chichester: John Wiley, 13288-13311.

7. Lenglet, M., Le Calonnec, D., Durr, J., Hannoyer, B., Calas, G., Petiau, J., Jeannot, F. (1983). Contribution de la spectrometrie $\mathrm{X}$ d'oxides de per a valence mixte. Analise de la structure fine du seuil d'absorption K. Materials Research Bulletin, 18 (8), 935-944. doi: 10.1016/0025-5408(83)90004-1

8. Sacurai, S., Sasaki, S., Okube, M., Ohara, H., Toyoda, T. (2008). Cation distribution and valence state in $\mathrm{Mn}-\mathrm{Zn}$ ferrite examined by synchrotron X-rays. Physica B: Condensed Matter, 403 (19-20) 3589-3595.

doi: $10.1016 /$ j.physb.2008.05.035

9. Fatemi, D. J., Harris, V. G., Chen, M. X., Malik, S. K., Yelon, W. B., Long, G. J., Mohan, A. (1999). X-ray absorption, neutron diffraction, and Mössbauer effect studies of MnZn-ferrite processed through high-energy ball milling. Journal of Applied Physics, 85 (8), 5172-5174. doi: 10.1063/1.369114

10. Gupta, R. G., Mendiratta, R. G. (1977). Mössbauer stidies in $\mathrm{Zn}_{\mathrm{x}} \mathrm{Mn}_{1-\mathrm{x}} \mathrm{Fe}_{2} \mathrm{O}_{4}$ systems. Journal of Applied Physics, 48 (2), 845-848. doi: 10.1063/1.323642

11. Nasr Isfahani, M. J., Myndyk, M., Šepelăk, V., Amighian, J. (2009). A Mössbauer effect investigation of the formation of MnZn nanoferrite phase. Journal of Alloys and Compounds, 470 (1-2), 434-437.

doi: 10.1016/j.jallcom.2008.02.113

12. Kopayev, O. V. (1995). Osoblyvosti rentgenofluoreszentnogo analizu ferytiv u tonkich probach. Visnyk Prikarpatskogo universitetu. Serija prirodnycho-matematychnych nauk, 1, 15-23.

13. Meisel, A., Leonhardt, G., Szargan, R. (1980). Rentgenovskie spektry i chimicheskaja svjaz. Kiev: Naukova dumka, 420.

14. Vandenberghe, R. E., De Grave, E.; Long, G. J., Grandjean, F. (Eds.) (1989). Mössbauer effect studies of oxidic spinels. Mössbauer spectroscopy applied to inorganic chemistry. Vol, 3. New York: Plenum Press, 59-182. doi: 10.1007/978-14899-2289-2 3

15. Kopayev, O. V. (2008). Magnitne vporjadkuvannja v structuri nikelevych ferytiv. Physics and Chemistry of Solid State, $9(1), 58-63$.

16. Campbell, S. J., Aubertin, F.; Long, G. J., Grandjean, F. (Eds.) (1989). Evaluation of distributed hyperfine parameters. Mössbauer spectroscopy applied to inorganic chemistry. Vol. 3. New York: Plenum Press, 183-242. doi: 10.1007/9781-4899-2289-2 4

17. Archarov, V. I., Samoylenko, Z. A., Paschenko, V. P., Nesterov, A. M. (1991). Izv. AN SSSR. Neorgan. Mater., 27 (10), 2184-2189.

18. Paschenko, V. P., Khorjakov, A. A., Paschenko, V. P., Shemjakov, A. A., Zacharchenko, S. I., Kopayev, A. V. (2009). Defektnost nanostruktury i magnitoresistivnyje svoystva marganets-zinkovych ferritov. Metallofiz. noveyshie technolog., 31 (2), 249-261.

Рекомендовано до публікачії д-р фіз.-мат. наук Остафійчук Б. К. Дата надходження рукопису 25.12.2014

Копаев Александр Венедиктович, кандидат технических наук, доцент, кафедра материаловедения и новейших технологий. Прикарпатский национальный университет им. В. С. Стефаника, ул. Шевченко, 57, г. Ивано-Франковск, Украина, 76025

E-mail: iskander.vened@,rambler.ru

Мокляк Владимир Владимирович, кандидат физико-математических наук, докторант, Институт металлофизики НАНУ им. Г. В. Курдюмова, бул. акад. Вернадского, 36, г. Киев, Украина, 03680

Бушкова Вера Степановна, кандидат физико-математических наук, младший научный сотрудник, кафедра материаловедения и новейших технологий, Прикарпатский национальный университет им. В. С. Стефаника. ул. Шевченко, 57, г. Ивано-Франковск, Украина, 76025 